\title{
A direita, a esquerda e a democracia: os valores políticos dos parlamentares paranaenses $(1995-2002)^{\prime}$
}

\section{Renato M. Perissinotto \\ Mariana B. Braunert}

Universidade Federal do Paraná

\begin{abstract}
Resumo
Embora a maior parte dos estudos sobre cultura política tenha por foco a análise dos valores políticos dispersos na população como um todo, as atitudes partilhadas por aqueles que operam diretamente o sistema político - as elites - já tem sua importância reconhecida, principalmente no que concerne ao impacto que exerce sobre a qualidade e estabilidade do regime democrático. Levando em conta que a relação entre os valores políticos das elites e a democracia deve passar pela análise das atitudes das elites também regionais e não só nacionais, este artigo analisa, com base em dados de survey, as opiniões políticas dos parlamentares paranaenses do período de 1995 a 2002. Pretende-se apontar a importância que a variável "posição ideológica" possui para entender as diferenças de adesão ao sistema democrático encontradas entre os parlamentares de esquerda e de direita.
\end{abstract}

Palavras-chave: elite parlamentar, valores políticos, posição ideológica, Brasil

\begin{abstract}
Although most of the studies on political culture stress on attitudes of the population as a whole, some researchers have dedicated their attention to the political values of the national political elite. We believe that the same attention must be paid to the political attitudes of regional political elites, since they operate central parts of the political system (the sub-national units of the political system). This article analyses the political opinions of the members of the Paraná state parliament, based on data collected by a survey. We intend to indicate the importance of the "ideological position" variable to understand the differences in the intensity of the adhesion to the democratic system between the right and left wing members of the Paraná state parliament.
\end{abstract}

Key words: parliamentary elite, political attitudes, ideological position, Brazil

\footnotetext{
${ }^{1}$ Os autores gostariam de agradecer aos pareceristas anônimos de Opinião Pública pelas sugestões feitas ao texto e a Ednaldo Aparecido Ribeiro, pela consultoria estatística.
} 


\section{Apresentação}

Uma extensa literatura considera a existência de orientações subjetivas favoráveis à democracia numa dada população um fator decisivo para o êxito ou o fracasso desse regime em um determinado país. Embora Almond e Verba (1989) sejam os precursores mais conhecidos dessa corrente, a importância da dimensão cultural dos fenômenos políticos e, mais especificamente, o seu impacto sobre o advento e a estabilidade dos regimes democráticos são reconhecidos como fundamentais por diversos autores que se dedicam às análises empíricas da democracia, ainda que, para alguns deles, a variável cultural esteja sempre conjugada a fatores de ordem econômica e política (INGLEHART, 1988)².

A grande maioria desses estudos dedica-se a analisar os valores políticos dispersos na população como um todo. Uma série de outros trabalhos, porém, insiste na importância de estudar a cultura política das elites, visto ser esse um grupo portador de crenças políticas mais articuladas, que se coloca à frente dos processos decisórios e cuja conduta afeta necessariamente o funcionamento do sistema político (CONVERSE, 1964; DAHL, 1997, cap. 8; LIJPHART, 1980, p. 50; VERBA, 1980, p. 404). De fato, como dizem Power e Jamison, se "a visão convencional na pesquisa sobre cultura política é a de que qualquer sistema político deve desenvolver um sistema cultural de apoio ou corre o risco de um eventual rompimento" (POWER e JAMISON, 2005, p. 75), então não há porque limitar os estudos de cultura política à população como um todo, deixando de lado justamente aqueles responsáveis por operar diretamente as instituições democráticas ${ }^{3}$.

De nossa parte, pensamos ainda que se alguma relação há entre, de um lado, a estabilidade e a qualidade da democracia e, de outro, os valores políticos das elites, essa relação passa também, forçosamente, pelas elites regionais e não apenas por aquelas que atuam no âmbito nacional, objeto de estudo de grande parte dos trabalhos sobre o tema (REIS e CHEIBUB, 1995; LIMA e CHEIBUB, 1996). $\mathrm{Na}$ medida em que as elites políticas regionais são operadores estratégicos de

\footnotetext{
${ }^{2}$ Essa concepção encontra resistências entre aqueles que enfatizam o desenho institucional e acreditam que, para o sucesso da democracia, é suficiente a existência de instituições formais democráticas. Ver, por exemplo, Santos (2004) e Limongi (2002).

3 Talvez um dos maiores problemas dos estudos de cultura política de populações nacionais é, segundo Wedeen, trabalhar com um conceito de cultura que pressupõe uma coerência interna e uma estabilidade difíceis de sustentar empiricamente. Nesse sentido, o estudo de elites políticas reconhece, de saída, a existência de uma divisão básica no interior da cultura política de uma nação. Na verdade, como veremos adiante, mesmo no interior de grupos minoritários, como as elites políticas, é improvável encontrarmos uma cultura totalmente homogênea (WEDEEN, 2002, p. 720). Lembre-se, ainda, que o estudo dos valores políticos das elites justifica-se também em função da influência que tais valores podem exercer sobre as opiniões da população em geral, notadamente quando esta não encontra à sua disposição fontes alternativas de informação. Quanto a este ponto, ver Druckman e Nelson (2003).
} 
partes importantes do sistema político (isto é, as unidades políticas sub-nacionais), parece-nos fundamental levar em consideração suas atitudes, não apenas no que concerne à estabilidade do sistema democrático, mas também à qualidade da democracia que se pretende consolidar no Brasil. Deve-se observar ainda que a viabilidade de determinadas políticas públicas promotoras de uma maior igualdade passa não apenas pela organização da "sociedade civil", como se tem dito comumente, mas também pela disposição das minorias politicamente ativas em adotá-las como objetivos políticos.

Nesse sentido, acreditamos que os estudiosos da cultura política devem voltar os seus olhares para os diversos sistemas políticos regionais, assim como vêm fazendo alguns analistas do poder legislativo (SANTOS, 2001). Na ausência de pesquisas sobre elites de outros estados, o presente trabalho não pode ser visto como um "estudo de caso", no sentido dado a essa expressão por John Gerring (2004). Segundo este autor, um estudo de caso é uma análise intensiva de "uma única unidade com vistas a produzir generalizações para outro conjunto de unidades" (GERRING, 2004, p. 352). Nesse sentido, tais estudos comportam duas dimensões: "são, ao mesmo tempo, estudos tout court e estudos de caso de algo mais geral” (p. 345). Como um estudo tout court, a população analisada restringe-se à unidade sob investigação; como um estudo de caso, a população inclui forçosamente "unidades adjacentes". Dessa forma, na falta de informações sobre as "unidades adjacentes" (isto é, sobre as demais elites políticas regionais), é impossível para nós identificar quais proposições acerca da elite paranaense expressariam características da elite brasileira como um todo e que, portanto, fariam do nosso objeto um "caso exemplar" a ser estudado de maneira mais intensa. Por essa razão, este texto representa um estudo tout court, cujas proposições visam a descrever as características da unidade em análise: a elite parlamentar do estado do Paraná, no período especificado. Obviamente, esta é uma situação que precisa ser superada no que diz respeito ao conhecimento sobre as elites políticas no Brasil.

Com vistas a dar uma contribuição nesse sentido, o objetivo deste artigo é apresentar e analisar os valores políticos da elite parlamentar paranaense durante as $13^{a}$ e $14^{a}$ legislaturas $(1995-2002)^{4}$ em relação ao sistema político democrático ${ }^{5}$.

\footnotetext{
4 Este artigo apresenta o resultado parcial da pesquisa "Quem governa? Mapeando as elites políticas paranaenses (1995-2002)", realizada pelo Núcleo de Pesquisa em Sociologia Política Brasileira do Departamento de Ciências Sociais da UFPR. A pesquisa tinha como objetivo aplicar um survey sobre origem social, carreira e valores políticos a três setores da elite política regional: os parlamentares, os dirigentes do Estado e os líderes partidários. O nosso universo inicial era composto de 167 pessoas (68 dirigentes do Estado, 78 parlamentares e 21 líderes partidários), das quais 108 foram entrevistadas, obtendo-se, assim, uma taxa de retorno geral de $65 \%$. No que diz respeito exclusivamente aos parlamentares, conseguimos aplicar o questionário a 44 indivíduos, obtendo uma taxa de retorno de $56,5 \%$. Desses 44 parlamentares, três foram descartados para a presente análise por circularem por
} 
Para tanto, o texto que segue está organizado da seguinte maneira: na primeira parte, analisamos o grupo dos parlamentares como um todo, apresentando algumas freqüências simples sobre sua adesão ao regime democrático, sobre as condições em que admitem ou não o fim deste regime e sobre sua visão de democracia; na segunda parte, abandonamos a abordagem dos parlamentares como um grupo e passamos a estudá-los a partir de suas divisões internas, notadamente a origem ocupacional de seus membros, o seu nível de escolaridade e, por fim, a sua posição no espectro ideológico (esquerda-direita). Sugerimos que esta última variável é mais importante para entender algumas das diferenças encontradas entre os parlamentares quanto às suas opiniões sobre a democracia, em especial a variação da intensidade da adesão a esse sistema político encontrada entre deputados de direita e de esquerda.

\section{Os parlamentares e a democracia no Paraná}

\section{A adesão à democracia}

Quando observamos as respostas dadas pelos parlamentares paranaenses acerca de sua preferência pela democracia, é fácil a constatação de sua ampla adesão a essa forma de governo.

A adesão à democracia como a melhor forma de governo pela quase totalidade da elite parlamentar paranaense $(92,7 \%$, Tabela 1) situa-se em níveis muito mais altos que os encontrados entre as populações brasileira e latinoamericana como um todo. Segundo José Álvaro Moisés, de setembro de 1989 a março de 1993, a porcentagem dos brasileiros que preferiam a democracia a qualquer outro regime político variou de um mínimo de 43\% a um máximo de 59\% dos entrevistados (MOISÉS, 1995, p. 127). Os dados do Latinobarómetro sobre a adesão da população brasileira à democracia são ainda mais baixos. Segundo este instituto de pesquisa, entre 1996 e 2004, a percentagem de brasileiros que preferiam a democracia a qualquer outra forma de governo nunca ultrapassou a barreira dos 50\%, atingindo o mínimo de 30\% em 2001 e situando-se, em 2004, no

\footnotetext{
diversos setores da elite regional. Portanto, todas as considerações feitas no presente artigo referem-se aos 41 parlamentares restantes ( 11 da $13^{a}, 7$ da $14^{\mathrm{a}}$ legislatura e 23 de ambas). A pesquisa contou com o apoio financeiro da Fundação Araucária e do CNPq. Por fim, vale lembrar que o mesmo survey está sendo aplicado para as elites políticas paranaenses do período 2003-2006 (governo Roberto Requião).

5 Preferimos falar em "valores políticos" ou "atitudes políticas" já que o nosso trabalho não poderia, de fato, ser caracterizado como um estudo de "cultura política", e isso por duas razões. Primeiramente, porque, para tanto, seria necessário lidar com questões referentes ao processo de socialização (familiar e político) pelo qual passaram os indivíduos aqui analisados; em segundo lugar, e como decorrência do que foi dito anteriormente, a cultura, por definição, refere-se a atitudes profundamente sedimentadas nos agentes, o que só poderia ser captado por meio de um estudo longitudinal.
} 
patamar de $41 \%$. A média latino-americana foi bem mais alta, variando de um mínimo de 41\%, em 2001, a um máximo de 62\%, em 1997/1998, e, por fim, atingindo $53 \%$ em 2004.

Quando se trata, porém, de analisar a adesão ao regime democrático por parte das elites políticas parlamentares na América Latina, os dados são muito próximos daqueles encontrados por nós para os parlamentares paranaenses. No caso do Chile, em 1997, $84,1 \%$ dos seus parlamentares avaliavam que a democracia era a melhor forma de governo, número que subiu para 90,7\% em 2001; para o Equador, esses números são 92,9\%, em 1998, e 87,8\%, em 2002; para a Venezuela, 95,6\%, em 1993, e 90,1\%, em $2000^{6}$.

Tabela 1

Adesão à democracia dos parlamentares do estado do Paraná, 1995-2002

\begin{tabular}{|l|c|c|}
\hline Opções & N & $\%$ \\
\hline A democracia é sempre a melhor forma de governo & 38 & 92,7 \\
\hline A democracia às vezes é a melhor forma de governo & 3 & 7,3 \\
\hline A democracia nunca é a melhor forma de governo & 0 & 0 \\
\hline É indiferente ter ou não uma democracia & 0 & 0 \\
\hline Total & 41 & 100 \\
\hline
\end{tabular}

Fonte: Núcleo de Pesquisa em Sociologia Política Brasileira/UFPR.

No entanto, a adesão à democracia anunciada na tabela acima não nos diz nada a respeito de quão intensamente os entrevistados aderem ao regime. A partir dos dados apresentados até o momento, poderíamos supor que, sendo a democracia, para a maioria esmagadora dos parlamentares, sempre a melhor forma de governo, eles não aceitariam a suspensão desse sistema político em hipótese alguma. Entretanto, não é o que ocorre.

Para testar a intensidade desta adesão, apresentamos aos parlamentares algumas afirmações segundo as quais certas condições justificariam o fim da democracia. Eles deveriam concordar ou discordar de cada afirmação, avaliando se o fim do regime democrático seria ou não aceitável nas situações dadas. As respostas estão na Tabela 2 a seguir.

\footnotetext{
6 Para os dados sobre a população em geral, ver Informe - Resumen Latinobarómetro 2004: uma década de mediciones, p. 4.5 (www.latinobarómetro.org). Ver também Muszynski e Mendes (1990, p. 70), para uma comparação entre Brasil, Argentina e Chile; os dados sobre as elites parlamentares do Chile, Equador e Venezuela foram produzidos pelo Instituto Interuniversitario de Iberoamérica - Universidad de Salamanca.
} 
PERISSINOTTO, R. M.; BRAUNERT, M. B. A direita, a esquerda e a democracia

Tabela 2

Condições em que concorda ou discorda com o fim da democracia (parlamentares do estado do Paraná, 1995-2002)

\begin{tabular}{|l|c|c|c|c|}
\hline \multicolumn{1}{|c|}{ Questões } & Concorda & Discorda & NR & Total \\
\hline Ameaça generalizada à propriedade & $41,5 \%$ & $58,5 \%$ & $0 \%$ & $100 \%$ \\
privada & $(17)$ & $(24)$ & $(0)$ & $(41)$ \\
\hline Ameaça generalizada aos valores & $39 \%$ & $61 \%$ & $0 \%$ & $100 \%$ \\
morais e religiosos & $(16)$ & $(25)$ & $(0)$ & $(41)$ \\
\hline Ameaça à ordem pública em função & $29,3 \%$ & $68,3 \%$ & $2,4 \%$ & $100 \%$ \\
de crise econômica & $(12)$ & $(28)$ & $(1)$ & $(41)$ \\
\hline Descontrole da corrupção & $41,4 \%$ & $58,5 \%$ & $0 \%$ & $100 \%$ \\
& $(17)$ & $(24)$ & $(0)$ & $(41)$ \\
\hline Quebra da hierarquia das instituições & $22 \%$ & $75,6 \%$ & $2,4 \%$ & $100 \%$ \\
militares & $(9)$ & $(31)$ & $(1)$ & $(41)$ \\
\hline O fim da democracia não é aceitável & $65,9 \%$ & $34,1 \%$ & $0 \%$ & $100 \%$ \\
em hipótese alguma & $(27)$ & $(14)$ & $(0)$ & $(41)$ \\
\hline
\end{tabular}

Fonte: Núcleo de Pesquisa em Sociologia Política Brasileira/UFPR.

Em certa medida, a forte adesão anunciada anteriormente se confirma nos dados apresentados na Tabela 2, já que em nenhuma das condições apresentadas aos parlamentares a opção "concorda" foi majoritária (exceto na última assertiva, cujo resultado se inverte, como esperado, em coerência com as respostas anteriores). Ainda assim, é significativo que um número razoável dos entrevistados diz concordar com o fim da democracia em algumas circunstâncias. Nesses casos, a ameaça generalizada à propriedade privada foi a condição que mais motivou os parlamentares a aceitar o fim da democracia, seguida pelo descontrole da corrupção e pela ameaça aos valores morais e religiosos de nossa sociedade. Chama a atenção que, tantos anos após o golpe de 1964, uma eventual crise na hierarquia militar não é vista pelos entrevistados como motivo para suspender o regime democrático ${ }^{7}$. A síntese dessas orientações encontra-se nas respostas à última questão: $34,1 \%$ dos deputados discordam da afirmação segundo a qual a democracia não pode ser suspensa em hipótese alguma, isto é, aceitam o seu fim nas circunstâncias especificadas ou em alguma outra situação não definida pelo nosso questionário ${ }^{8}$.

\footnotetext{
7 O que iria ao encontro da tendência encontrada por Lima e Cheibub, no seu estudo sobre elites estratégicas (LIMA e CHEIBUB, 1994), e das considerações feitas por Moisés (2005, p. 37).

8 É importante apontar que para as alternativas "ameaça generalizada à propriedade privada", "ameaça generalizada aos valores" e "descontrole da corrupção" a porcentagem dos que escolheram a opção "concorda" é maior do que a dos que escolheram a opção "discorda" na última alternativa ("o fim da democracia não é aceitável em hipótese alguma"). Isso evidencia, nesse caso, uma incongruência nas
} 
Essas questões podem ser analisadas à luz de uma discussão teórica recorrente sobre a relação entre regime democrático e cultura política. De um lado, uma ampla literatura defende a idéia de que a democracia só se sustenta se a população a ela submetida e, principalmente, a elite política que a operacionaliza, estiverem imbuídas de um "espírito democrático" (ALMOND e VERBA, 1989; DAHL, 1997; INGLEHART, 1988) ${ }^{9}$; de outro, alguns estudiosos afirmam que nenhum dado autoriza esse tipo de relação causal e que o surgimento e a permanência do regime democrático dependem muito mais do cálculo estratégico dos atores políticos relevantes do que de sua cultura política (PRZEWORSKI, CHEIBUB e LIMONGI, 2003; SANTOS, 2004).

A Tabela 2, a acreditar na resposta dos entrevistados, conjuga as duas situações. Há alguns parlamentares que vêem a democracia como um valor a ser respeitado acima de tudo. Nesses casos, o regime deveria ser mantido, mesmo em caso de ameaças generalizadas à ordem pública, à propriedade e à tradição. No entanto, há aqueles que aceitam a democracia e, até mesmo, julgam-na como a melhor forma de governo, mas que, no entanto, defendem a sua supressão caso valores que the são fundamentais sejam atingidos pela continuidade do sistema. Nesses casos, a sobrevivência da democracia está intimamente ligada à relação custo/benefício que ela pode trazer para os atores políticos estratégicos.

Nossos dados não permitem nenhuma conclusão definitiva a respeito desse assunto. No entanto, as respostas dadas às questões acima enunciadas revelam que a oposição simplista entre "democracia como valor" e "democracia como cálculo" muito provavelmente não representa a melhor saída analítica. É provável que, na maioria das vezes, no interior da elite política de um sistema democrático, encontrem-se indivíduos com uma visão predominantemente valorativa de democracia e outros para os quais esta forma de governo traga, antes de tudo, mais benefícios do que prejuízos. Como se sabe, as análises de Robert Dahl em Poliarquia apontam exatamente para essa direção. Segundo este autor, a probabilidade de sucesso de um regime poliárquico é tanto maior se encontrarmos entre os membros da elite política as seguintes características: de um lado, indivíduos que

\footnotetext{
respostas: alguns indivíduos responderam, por exemplo, que aceitariam o fim do regime no caso de ameaça à propriedade privada, mas depois concordaram que o fim da democracia não é aceitável em hipótese alguma. Os casos restantes, em que a porcentagem de "concorda" é menor do que a de "discorda" na última alternativa, sugerem que, para alguns respondentes, existem outras situações, não apresentadas na questão, que justificariam o fim da democracia. Ou seja, eles discordam quanto à suspensão do regime democrático nas situações apresentadas, mas também discordam da última afirmação, pois aceitariam o fim da democracia em outras situações não contempladas pela nossa questão.

${ }^{9}$ Nessa perspectiva, não apenas o capitalismo exigiria um "espírito" para se desenvolver, como lembra Max Weber, mas também a democracia demandaria dos cidadãos uma disposição subjetiva específica para que pudesse funcionar "adequadamente".
} 
avaliem que tolerar a existência da oposição seja mais vantajoso (isto é, menos custoso) do que o ato de suprimi-la e, de outro, que esses mesmos indivíduos estejam, em alguma medida, imbuídos de valores democráticos. Dito de outra forma, para Dahl, a existência de uma cultura política democrática é uma das condições que incentiva os atores políticos relevantes a optarem pela tolerância, daí a sua importância para entender os processos de surgimento e estabilização das democracias $^{10}$.

\section{Qual democracia?}

Embora o apoio dos parlamentares à democracia como idéia geral e abstrata seja em si mesmo relevante, pois expressa a adesão do grupo ao regime, os dados acima nada nos dizem sobre o conteúdo do termo "democracia". Sabemos que os parlamentares defendem esse regime político, mas não podemos definir, a partir dos dados vistos até o presente momento, a que tipo de democracia se referem. Nesse sentido, o resultado visto até agora é muito vago e, até certo ponto, esperado. Constatado o apoio dos parlamentares ao regime, é fundamental caracterizar a qual democracia aderem.

Para tanto, submetemos os entrevistados a algumas questões que enfatizavam o problema da igualdade socioeconômica e da participação política. 0 nosso objetivo era verificar em que medida os deputados atribuíam alguma importância a esses dois fatores para a caracterização mais precisa do regime democrático. Em outras palavras, pretendíamos saber se o grupo apoiaria uma visão igualitária e/ou participativa de democracia ou se predominaria entre seus membros uma concepção puramente eleitoral, isto é, uma visão que reduz esse regime político ao mecanismo de escolha dos governantes por meio de eleições competitivas.

Para testar a adesão dos parlamentares a uma visão de democracia que enfatiza a igualdade socioeconômica (e não apenas política), pedimos que eles se posicionassem como favoráveis ou contrários em relação a determinadas políticas

\footnotetext{
${ }^{10}$ Ao recensear criticamente a literatura sobre confiança política, José Álvaro Moisés observa que alguns autores "postularam que os instrumentos de mensuração empírica do fenômeno [da confiança nas instituições] deveriam ter em conta que os cidadãos combinam, embora não necessariamente de forma semelhante ou equilibrada, critérios normativos e racionais relativos à probidade, sentido de justiça e eficácia da ação dos atores correspondentes para avaliar e julgar governos, governantes e instituições políticas" (MOISÉS, 2005, p. 45 e 55). Nesse sentido, parece que a literatura encaminha-se para a superação da oposição pura e simples entre cultura e racionalidade, tanto no que diz respeito ao estudo das atitudes das elites políticas como daquelas dispersas pela população como um todo. Quanto a necessidade de combinar uma análise culturalista e racional dos valores políticos, ver também Lane (1992). Um comportamento exclusivamente racional das elites frente às instituições democráticas poderia gerar um uso instrumental das mesmas o que, por sua vez, poderia aumentar o nível de desconfiança da população em relação à democracia e aos políticos. Ver também Power e Jamison, (2005, p. 80-82).
} 
sociais que, uma vez implementadas, poderiam promover a construção de uma ordem social mais igualitária. Essa questão é importante porque $82,9 \%$ dos deputados avaliam que o Brasil é uma democracia, mas, ao mesmo tempo, 87,8\% deles acham que a desigualdade de renda é um obstáculo à consolidação do regime e $78 \%$ atribuem à ganância das elites o mesmo papel. Trata-se de saber, então, em que medida eles aceitariam políticas que pudessem superar tais obstáculos. Os resultados encontram-se na Tabela 3 abaixo.

\section{Tabela 3}

Posição sobre políticas sociais igualitárias

(parlamentares do estado do Paraná, 1995-2002)

\begin{tabular}{|l|c|c|c|c|c|}
\hline \multicolumn{1}{|c|}{ Questões } & $\begin{array}{c}\text { Totalmente } \\
\text { favorável }\end{array}$ & $\begin{array}{c}\text { Parcialmente } \\
\text { favorável }\end{array}$ & $\begin{array}{c}\text { Parcialmente } \\
\text { contrário }\end{array}$ & $\begin{array}{c}\text { Totalmente } \\
\text { contrário }\end{array}$ & Total \\
\hline $\begin{array}{l}\text { Sistema universitário } \\
\text { gratuito }\end{array}$ & $\begin{array}{c}58,5 \% \\
(24)\end{array}$ & $\begin{array}{c}31,7 \% \\
(13)\end{array}$ & $\begin{array}{c}7,3 \% \\
(3)\end{array}$ & $\begin{array}{c}2,4 \% \\
(1)\end{array}$ & $\begin{array}{c}100 \% \\
(41)\end{array}$ \\
\hline Saúde pública universal & $80,5 \%$ & $19,5 \%$ & $0 \%$ & $0 \%$ & $100 \%$ \\
& $(33)$ & $(8)$ & $(0)$ & $(0)$ & $(41)$ \\
\hline Renda mínima para todos & $53,7 \%$ & $36,6 \%$ & $7,3 \%$ & $2,4 \%$ & $100 \%$ \\
& $(22)$ & $(15)$ & $(3)$ & $(1)$ & $(41)$ \\
\hline Cotas para negros nas & $22 \%$ & $43,9 \%$ & $12,2 \%$ & $22 \%$ & $100 \%$ \\
universidades públicas & $(9)$ & $(18)$ & $(5)$ & $(9)$ & $(41)$ \\
\hline Reforma agrária em terras & $9,8 \%$ & $43,9 \%$ & $24,4 \%$ & $22 \%$ & $100 \%$ \\
produtivas ou não & $(4)$ & $(18)$ & $(10)$ & $(9)$ & $(41)$ \\
\hline
\end{tabular}

Fonte: Núcleo de Pesquisa em Sociologia Política Brasileira/UFPR.

Como se vê, cotas para negros nas universidades públicas e reforma agrária são as questões a respeito das quais um maior número de parlamentares posicionase total ou parcialmente contrário: além de apenas 22\% serem totalmente favoráveis à primeira e 9,8\% à segunda, 22\% são totalmente contrários a ambas, número bastante alto se comparado ao de parlamentares que se posicionaram contrariamente às demais políticas públicas. Mesmo se agregarmos as respostas do que são, em alguma medida, favoráveis a essas duas políticas públicas, os percentuais (62,9\% e 53,7\%) ficam ainda bem abaixo daqueles encontrados para as outras políticas. A manutenção do atual sistema universitário, a universalização da saúde pública e a garantia de renda mínima para todos os cidadãos são, por sua vez, aquelas que recebem um maior apoio por parte do grupo: o percentual de parlamentares totalmente favoráveis a elas é, respectivamente, 58,5\%, 80,5\% e $53,7 \%$. Se, como fizemos para as políticas de cota e de reforma agrária, agregarmos as respostas favoráveis, os percentuais saltam para 90,2\%, 100\% e 
$90,3 \%$, respectivamente. Percebe-se, assim, claramente, um menor entusiasmo dos parlamentares paranaenses em relação à política de cotas para negros e à reforma agrária em terras produtivas e improdutivas.

Se a igualdade é um valor fundamental para uma concepção substantiva de democracia, a extensão das esferas de participação política disponíveis ao cidadão é o fator propriamente político que permite uma melhor caracterização do tipo de democracia a que se referem os parlamentares entrevistados ${ }^{11}$.

A fim de avaliar quão participativa é a visão de democracia a que aderem os parlamentares, apresentamos a eles questões sobre a necessidade de existirem esferas alternativas de participação política para que um regime pudesse ser efetivamente caracterizado como democrático. O nosso objetivo era ver em que medida os parlamentares definiriam como essencial à democracia, além do voto, formas de participação tais como os conselhos gestores, o plebiscito, o orçamento participativo e a participação direta de todos no processo decisório. Os resultados podem ser vistos na Tabela 4.

Tabela 4

Posição sobre ampliação da participação política (parlamentares do estado do Paraná, 1995-2002)

\begin{tabular}{|l|c|c|c|c|c|c|c|}
\hline \multicolumn{1}{|c|}{ Questões } & $\begin{array}{c}\text { Concorda } \\
\text { fortemente }\end{array}$ & Concorda & $\begin{array}{c}\text { Nem concorda } \\
\text { nem discorda }\end{array}$ & Discorda & $\begin{array}{c}\text { Discorda } \\
\text { fortemente }\end{array}$ & NR & Total \\
\hline Voto & $75,6 \%$ & $19,5 \%$ & $2,4 \%$ & $0 \%$ & $2,4 \%$ & $0 \%$ & $100 \%$ \\
& $(31)$ & $(8)$ & $(1)$ & $(0)$ & $(1)$ & $(0)$ & $(41)$ \\
\hline Plebiscito & $19,5 \%$ & $31,7 \%$ & $19,5 \%$ & $24,4 \%$ & $4,9 \%$ & $0 \%$ & $100 \%$ \\
& $(8)$ & $(13)$ & $(8)$ & $(10)$ & $(2)$ & $(0)$ & $(41)$ \\
\hline Conselhos & $29,3 \%$ & $41,5 \%$ & $9,8 \%$ & $17,1 \%$ & $0 \%$ & $2,4 \%$ & $100 \%$ \\
gestores & $(12)$ & $(17)$ & $(4)$ & $(7)$ & $(0)$ & $(1)$ & $(41)$ \\
\hline Orçamento & $24,4 \%$ & $34,1 \%$ & $17,1 \%$ & $19,5 \%$ & $2,4 \%$ & $2,4 \%$ & $100 \%$ \\
participativo & $(10)$ & $(14)$ & $(7)$ & $(8)$ & $(1)$ & $(1)$ & $(41)$ \\
\hline Participação & $22 \%$ & $39 \%$ & $4,9 \%$ & $26,8 \%$ & $4,9 \%$ & $2,4 \%$ & $100 \%$ \\
direta & $(9)$ & $(16)$ & $(2)$ & $(11)$ & $(2)$ & $(1)$ & $(41)$ \\
\hline
\end{tabular}

Fonte: Núcleo de Pesquisa em Sociologia Política Brasileira/UFPR.

\footnotetext{
11 Para uma síntese sobre a relevância da participação política como elemento-chave para definir o conceito de democracia, ver Pateman (1992, p. 9-63). A mesma Carole Pateman, dentre outros, critica Almond e Verba por operacionalizarem, no survey que aplicaram, um único modelo de democracia em relação ao qual os respondentes deveriam se posicionar, isto é, o modelo da democracia anglo-saxã. Questões sobre obstáculos socioeconômicos à democracia e sobre formas alternativas de participação política que não o voto podem atenuar esse problema, na media em que permitem ao entrevistado optar por outras visões de democracia. Evidentemente, a disposição para adotar uma ou outra estratégia de pesquisa tem tudo a ver com a perspectiva normativa do analista.
} 
O que se percebe na Tabela 4 é que, entre os parlamentares paranaenses entrevistados, a democracia permanece ainda fortemente associada ao procedimento eleitoral: 75,6\% "concordam fortemente" que só há democracia se houver a participação do cidadão pelo voto. O número é bastante alto se comparado a outras formas possíveis de participação: somente 29,3\% (a taxa mais alta depois da adesão ao voto), por exemplo, "concordam fortemente" com a idéia de que a participação do cidadão por meio de conselhos gestores de políticas públicas é essencial para o bom funcionamento do sistema democrático. A participação direta dos cidadãos no processo decisório, característica central de uma visão radical (rousseauniana) de democracia, e o plebiscito receberam o menor apoio dos parlamentares. Respectivamente, apenas $22 \%$ e $19,5 \%$ deles disseram concordar fortemente com a afirmação de que tais procedimentos são essenciais à forma de governo democrática. Mesmo somando os percentuais das respostas favoráveis ("concorda fortemente" e "concorda"), os deputados paranaenses revelam uma propensão bem menor a considerar as formas alternativas de participação tão essenciais à democracia quanto o voto. Enquanto este último obtém $95,1 \%$ de respostas favoráveis, o plebiscito, os conselhos gestores, o orçamento participativo e a participação direta obtêm 51,2\%, 70,8\%, 58,8\% e 61\%, respectivamente.

Assim, pode-se concluir por hora que, não obstante haja adesão dos parlamentares à democracia como melhor forma de governo possível, predomina uma visão eleitoral desse regime, na qual o instrumento do voto constitui-se na sua característica essencial. Essa visão tem como contrapartida um apoio restrito e fragmentado às formas ampliadas de participação política. Condizente com essa observação é o fato de $48,8 \%$ dos deputados das legislaturas analisadas concordarem com a idéia de que a política é uma atividade demasiadamente complexa e, por isso, deve ser monopólio das lideranças políticas ${ }^{12}$. Por sua vez, o apoio dos parlamentares a uma democracia igualitária do ponto de vista social dirige-se preferencialmente, como vimos, ao acesso de todos os cidadãos aos serviços básicos e à idéia de redistribuição de renda, predominando claramente a defesa de um sistema público de saúde. No entanto, manifestam um apoio bem menos entusiasmado às modificações estruturais mais inclusivas, como, por exemplo, a reforma agrária e as ações afirmativas que beneficiem minorias étnicas.

\footnotetext{
$12 \mathrm{O}$ mesmo percentual optou pela posição contrária. Vale observar, porém, que essa questão é muito mais "antipática" do que as perguntas feitas sobre as formas ampliadas de participação. Ainda assim, grande parte dos entrevistados não hesitou em concordar com uma afirmação que apontava claramente para uma visão elitista da política. O resultado por nós encontrado, vale lembrar, está em consonância com outros estudos que apontam para o predomínio de uma visão hierárquica e elitista da política entre as elites no Brasil. Ver, por exemplo, Lima e Cheibub (1996).
} 


\section{A esquerda, a direita e a democracia}

Os dados apresentados refletem a adesão dos parlamentares paranaenses a uma concepção de democracia que, por um lado, tem no voto a sua mais importante característica institucional e, por outro, identifica a igualdade social com políticas públicas que limitem a ação do Estado aos chamados "serviços básicos", notadamente a saúde pública ${ }^{13}$. No entanto, os parlamentares estudados não formam um grupo homogêneo. Ao contrário, podemos encontrar diferenças significativas entre eles do ponto de vista da sua escolaridade, da sua origem social e, o que mais nos interessa, no que diz respeito ao seu auto-posicionamento no espectro ideológico (esquerda-direita). Neste item analisamos em que medida essas variáveis explicam a adesão à democracia e o tipo de democracia a que os entrevistados aderem. Para colocar a questão diretamente: ter uma dada origem social, possuir um certo grau de escolaridade e ser de esquerda ou de direita afetam ou não a visão de democracia dos nossos entrevistados e a intensidade com que aderem a este regime? 0 cruzamento dessas variáveis com os resultados obtidos nos permite explorar as clivagens existentes no interior do grupo em questão.

No que diz respeito à ocupação que o entrevistado exerceu por mais tempo antes do período em que entrou no grupo das elites parlamentares do Paraná, a nossa suposição era de que o tipo de ocupação profissional poderia afetar a intensidade da adesão do indivíduo à democracia, assim como o tipo de democracia que ele defende. A suposição é teoricamente plausível, pois alguns estudos demonstram que a socialização profissional pode afetar a "cultura política" dos indivíduos (ALMOND e VERBA, 1989; PATEMAN, 1992 e 1980), e, além disso, algumas ocupações constituem-se, pela sua própria natureza, em fontes privilegiadas para o recrutamento político (LOVE, 1982; CARVALHO, 2003; RODRIGUES, 2002). No caso dos indivíduos que compõem o nosso universo de pesquisa, entretanto, não detectamos nenhuma atividade profissional que pudesse assumir essa posição, tampouco qualquer relação significativa entre a ocupação exercida ao longo da vida e a posição do indivíduo frente ao sistema democrático. 0 resultado se repete quando utilizamos o nível de escolaridade do entrevistado. Os dados, portanto, apontaram um baixo poder explicativo dessas variáveis ${ }^{14}$.

\footnotetext{
13 Esse resultado se aproxima dos achados apresentados por Lamounier (1999, p. 41), em que as elites entrevistadas pelo autor concordam acentuadamente com a afirmação de que a atuação do Estado deve se restringir às "áreas clássicas", definidas naquela pesquisa como educação, justiça e segurança. No nosso caso, como visto na Tabela 3 acima, os parlamentares são amplamente favoráveis ao sistema universitário público e à universalização da saúde. Apenas a renda mínima destoa daquilo que poderíamos chamar de funções clássicas do Estado.

$14 \mathrm{Na}$ verdade, algumas poucas associações significativas foram detectadas em relação à escolaridade e à profissão. No primeiro caso, os coeficientes eram muito baixos, no segundo, mais altos. No entanto, em ambos os casos tais associações são muito esparsas. Por exemplo, quando cruzamos o nível de
} 
Em seguida, procuramos testar a hipótese de que eventuais diferenças no interior do grupo pesquisado pudessem aparecer se utilizássemos variáveis propriamente políticas, em vez de sociais, sugerindo, assim, que a socialização política seria mais importante para explicar as diferenças de atitude entre os parlamentares entrevistados do que sua socialização profissional (SEARING, 1987; PUTNAM, 2002). Para tanto, cruzamos os dados apresentados no início deste texto sobre a intensidade da adesão ao regime e o tipo de democracia defendido com a posição declarada pelo entrevistado no espectro ideológico. O nosso objetivo era saber se as opiniões sobre a democracia variavam de acordo com a posição ideológica dos parlamentares. Novamente, para sermos sintéticos, tratava-se de responder a seguinte questão: ser de direita ou de esquerda ainda conta?

Vale observar, inicialmente, que o entrevistado foi solicitado a se posicionar numa escala de 1 a 7 , na qual 1 representava a posição mais à esquerda e 7 a posição mais à direita. Certamente, esse auto-posicionamento sofre de alguns limites metodológicos, sendo o principal deles o fato de o entrevistado poder não reconhecer o conteúdo dos termos utilizados (algo improvável quando se trata de pesquisa com elites políticas) ou simplesmente mentir sobre o seu posicionamento ideológico. É importante lembrar ainda que a escala permite ao entrevistado encaixar-se na posição menos comprometedora frente à opinião média predominante no mundo político. Não por outra razão, "centro-esquerda" - uma posição que não se compromete com a insensibilidade social da direita nem com as posições "extremadas" e "ultrapassadas" da esquerda15 - tornou-se a opção escolhida pela maioria dos parlamentares, como apresenta a Tabela 5.

\footnotetext{
escolaridade do entrevistado com as seis questões relativas ao problema da participação política, encontramos associação apenas em uma delas. Isso se repete em todos os outros blocos de questões (políticas públicas e adesão à democracia). Para os cruzamentos com escolaridade, usamos o teste $D$ de Somer, uma medida de associação entre duas variáveis ordinais; para os cruzamentos com profissão, usamos o coeficiente de contingência, uma medida de associação entre variáveis nominais.

15 Isso nos permitiria explicar, por exemplo, a auto-definição de um deputado do PFL como sendo de centro-esquerda.
} 
Tabela 5

Posição ideológica dos parlamentares

(parlamentares do estado do Paraná, 1995-2002)

\begin{tabular}{|l|c|c|c|}
\hline Posição & $\mathbf{N}$ & $\%$ & Acumulado \\
\hline Extrema-esquerda & 1 & 2,4 & 2,4 \\
\hline Esquerda & 6 & 14,6 & 17,0 \\
\hline Centro-esquerda & 16 & 39,0 & 56,0 \\
\hline Centro & 10 & 24,4 & 80,4 \\
\hline Centro-direita & 5 & 12,2 & 92,6 \\
\hline Extrema-direita & 1 & 2,4 & 95,0 \\
\hline Não respondeu & 2 & 4,9 & 100 \\
\hline Total & 41 & 100 & 100 \\
\hline
\end{tabular}

Fonte: Núcleo de Pesquisa em Sociologia Política Brasileira/UFPR.

Ainda assim, resolvemos utilizar esse procedimento por três razões: primeiramente, porque ele se encontra bastante presente na literatura sobre o tema (MCDONOUGH, 1981; PUTNAM, 1976); em segundo lugar, porque evita o problema de transformar o posicionamento ideológico do parlamentar numa atribuição arbitrária do analista; e, por fim, porque quando cruzamos a posição ideológica auto-declarada com o grau de antipatia/simpatia dos entrevistados em relação aos partidos políticos pudemos perceber que os que se posicionam à esquerda do espectro ideológico tendem a ter mais simpatia por partidos de esquerda e serem mais antipáticos em relação a partidos de direita, o inverso ocorrendo com entrevistados que se situaram à direita do espectro ideológico. Isso sugere, portanto, uma certa coerência da posição ideológica auto-declarada ${ }^{16}$.

Conforme detalharemos a seguir, há uma maior associação entre a variável "posição ideológica do entrevistado" e a adesão ao sistema democrático do que entre aquela e o tipo de democracia a que aderem os parlamentares, seja do ponto de vista da igualdade, seja no que diz respeito à participação política. Ao cruzarmos a posição do parlamentar no espectro ideológico com a sua visão de democracia (igualitária ou procedimental; participativa ou representativa) não encontramos associações significativas $^{17}$.

\footnotetext{
16 Vale notar que as associações entre a posição no espectro ideológico e o grau de simpatia/antipatia do entrevistado foram significativas apenas em relação aos partidos mais importantes do cenário político paranaense no período analisado: PDT, PFL, PSDB, PT e PMDB. O teste de associação utilizado foi o coeficiente de contingência.

17 A única exceção refere-se à posição assumida pelos entrevistados no que diz respeito ao orçamento participativo como essencial à democracia. No entanto, mesmo aqui, a associação se deu num nível muito próximo do limite crítico de 0,05 (0,042). O teste utilizado foi o coeficiente de contingência.
} 
Como explicar essa situação em que ser de direita e ser de esquerda parece não fazer grande diferença quando se trata de adotar uma dada visão de democracia? Podemos apenas sugerir algumas explicações possíveis.

Primeiramente, parte desse problema pode decorrer, como já dissemos, do método utilizado por nós. O auto-posicionamento pode levar um entrevistado a se situar na posição ideológica menos comprometedora (no caso, "centro-esquerda"), mas, depois, fazer opções contrárias a essa posição ideológica, isto é, mais à direita, diminuindo a possibilidade de associação entre ambas. No entanto, vimos que a auto-declaração ideológica não é tão fantasiosa assim, visto que os parlamentares que se definem como de direita tendem a ter simpatia por partidos de direita e os deputados que se definem como de esquerda tendem a ser simpáticos em relação a partidos de esquerda.

Em segundo lugar, podemos supor que os parlamentares de esquerda sofreram, depois da queda do muro de Berlim, um cerco ideológico tão grande que acabaram por se aproximar de ideais políticos e sociais que antes não defendiam, tais como a democracia representativa (em vez de uma visão mais radical e mais participativa) e o sistema de mercado como a única organização econômica possível ou, pelo menos, como a mais bem sucedida. Fosse isso verdade, estaríamos presenciando, no âmbito da ala esquerda da elite parlamentar do Paraná, não apenas a derrocada do modelo socialista, mas, mais do que isso, a sua adesão aos valores ideológicos do mundo capitalista.

Por fim, a ausência de associações significativas quanto a este tema talvez possa ser explicada como um cálculo estratégico. O nosso universo de entrevistados é formado por políticos interessados em garantir sua reeleição, como é natural em um regime democrático. É plausível supor que esses indivíduos, de direita ou de esquerda, sejam muito sensíveis a questões sobre políticas públicas específicas, cuja implementação implicaria, necessariamente, uma redistribuição dos custos e benefícios sociais para partes significativas do eleitorado. Desse modo, haveria uma tendência a ocupar uma posição moderada sobre o tema, que não chocasse a visão de mundo do eleitor médio. O cálculo eleitoral levaria, então, políticos de direita e de esquerda a convergirem para um ponto central, eliminando assim associações entre o posicionamento ideológico auto-declarado e as opiniões sobre políticas públicas. Tais observações, entretanto, têm caráter totalmente especulativo, já que nossos dados não autorizam conclusões dessa natureza.

Contudo, os resultados são, como adiantamos, bem diferentes quando saímos do campo concreto das políticas públicas, por assim dizer, e passamos para a esfera bem mais abstrata da adesão à democracia e para as situações hipotéticas que poderiam justificar o fim desse regime. Ou seja, para usar uma terminologia mais técnica, a situação se altera quando abandonamos o problema das orientações 
subjetivas frente aos outputs do sistema político e olhamos para as atitudes da elite frente ao sistema político como um todo.

No início deste artigo, mostramos que $92,7 \%$ dos parlamentares afirmaram considerar a democracia a melhor forma de governo. Esse dado, no entanto, não nos revelava até que ponto os entrevistados estavam dispostos a sustentar o regime democrático. Como dissemos, para mensurar a "intensidade da adesão", questionamos os parlamentares sobre as condições em que aceitariam o fim da democracia. A nossa suposição era que a recusa em aceitar o fim da democracia correspondia a uma forte adesão a essa forma de governo.

Embora os deputados considerem a democracia sempre a melhor forma de governo, independente de serem de esquerda ou de direita, encontramos associações significativas (bem mais altas do que as encontradas quando usamos ocupação e escolaridade) entre a posição do deputado na escala ideológica e o fato de ele aceitar ou não o fim do regime democrático em determinadas condições (ver tabela em anexo). No nosso caso, quem é de direita tende a aceitar com mais facilidade o fim do regime democrático do que quem é de esquerda. As associações podem ser vistas no Quadro 1 a seguir:

\section{Quadro 1}

Associações entre posição ideológica e as condições em que o entrevistado aceita o fim da democracia (parlamentares do estado do Paraná, 1995-2002)

\begin{tabular}{|l|c|c|}
\hline Questões & $\begin{array}{c}\text { Coeficiente de } \\
\text { contingência }\end{array}$ & Sig. \\
\hline Ameaça generalizada à propriedade privada & 0,52 & 0,02 \\
\hline Ameaça generalizada aos valores morais e religiosos de nossa sociedade & 0,54 & 0,01 \\
\hline Descontrole da corrupção & 0,50 & 0,03 \\
\hline Ameaça ao estado pelo crime organizado & 0,49 & 0,03 \\
\hline O fim do regime democrático não é aceitável em hipótese alguma & 0,39 & 0,25 \\
\hline
\end{tabular}

Fonte: Núcleo de Pesquisa em Sociologia Política Brasileira/UFPR.

As associações apresentadas, ao lado da tabela em anexo, informam que quanto mais à esquerda se localiza o deputado no espectro ideológico, mais ele tende a aderir ao regime, na medida em que menos aceita o seu fim. É possível perceber, então, que os parlamentares paranaenses de esquerda e de direita que atuaram durante as $13^{a}$ e $14^{a}$ legislaturas não se diferenciam quanto ao tipo de democracia que defendem (mais ou menos igualitária, mais ou menos participativa), mas sim quanto à disposição de defender a manutenção do regime democrático nas circunstâncias acima enunciadas. 
Voltando, assim, à discussão feita no item anterior, podemos dizer que os deputados de direita tendem a ter uma relação mais estratégica com o regime democrático, isto é, tendem a aceitá-lo desde que valores que thes são essenciais (como a propriedade privada, a religião e a probidade pública) não sejam ameaçados. Isso significaria que para os deputados de esquerda a democracia seria um valor inatacável ou, por outra, que essa forma de governo deveria ser mantida quaisquer que fossem as circunstâncias sociais e políticas? Os dados do Quadro 1 não autorizam tais conclusões. Quanto a esse ponto, é preciso observar que as situações de risco apresentadas aos entrevistados referem-se mais a valores tradicionalmente caros à direita do que à esquerda. Seria lícito supor, portanto, que, confrontados com situações em que a democracia ameaçasse valores caros à esquerda, os deputados filiados a essa corrente aceitariam o fim do regime democrático. Nesse sentido, o último coeficiente do Quadro 1, o mais baixo de todos e o único não significativo, revela que mover-se no interior do espectro ideológico esquerda-direita está relacionado de forma frágil com a posição assumida frente à alternativa "o fim da democracia não é aceitável em hipótese alguma"18. Ou seja, de acordo com esses dados, a democracia não seria um valor universal nem para a ala direita nem para a ala esquerda dos parlamentares paranaenses no período analisado.

\section{Conclusão}

Este artigo procurou analisar o grau de adesão da elite política parlamentar paranaense ao regime democrático e especificar qual é o modelo de democracia defendido pelo grupo. Buscamos, além disso, verificar em que medida a profissão, a ocupação e a posição dos deputados no espectro ideológico se associavam aos seus valores políticos. Vimos que a elite política parlamentar por nós estudada pode ser compreendida, a princípio, como um grupo que adere ao regime democrático, pois o considera superior a outras formas de governo possíveis. No entanto, a propensão de parte dos parlamentares a aceitar o fim do regime nos levou a relativizar tal adesão. Vimos ainda que a visão de democracia dos parlamentares é fortemente marcada por uma concepção que identifica esse regime à participação pelo voto e à implementação de alguns serviços básicos pelo Estado. Os dados nos mostraram também que se, por um lado, a adesão a esse modelo minimalista de democracia é quase consensual entre o grupo como um todo, o grau de adesão ao regime, por outro lado, varia de acordo com a posição dos parlamentares no espectro ideológico esquerda-direita, isto é, quanto mais à esquerda ele se auto-

\footnotetext{
18 A ausência de associação quanto à última alternativa talvez possa ser explicada, em parte, pelas incongruências das respostas a esta questão identificadas na nota 11 acima.
} 
posiciona, mais fortemente tende a aderir ao sistema democrático. Tal associação, entretanto, diz respeito exclusivamente às condições apresentadas ao entrevistado, não sendo, portanto, passível de generalização para outras condições não testadas pelo nosso questionário.

Evidentemente, os dados apresentados ao longo deste artigo não nos permitem trabalhar de forma aprofundada as grandes questões teóricas sugeridas pela literatura de cultura política, notadamente o problema da relação causal entre valores políticos e estabilidade democrática, tema que, de resto, só pode ser adequadamente abordado por meio de uma análise que seja, ao mesmo tempo, diacrônica e comparativa. De qualquer forma, reiteramos que se alguma relação há entre orientações subjetivas e estabilidade democrática (além, é claro, com o tipo de democracia que se busca construir), essa relação deve passar forçosamente por aqueles que operam as unidades sub-nacionais do sistema político brasileiro. A nossa análise da elite parlamentar paranaense entre os anos de 1995 a 2002 e a aplicação do mesmo survey às elites do período corrente (2003-2006) pretendem ser uma contribuição nesse sentido. 


\section{Anexo}

Posicionamento do entrevistado no espectro ideológico e opinião sobre o fim da democracia (parlamentares do estado do Paraná, 1995-2002)

\begin{tabular}{|c|c|c|c|c|c|c|c|c|c|c|}
\hline \multirow[t]{2}{*}{$\begin{array}{c}\text { Posição } \\
\text { ideológica }\end{array}$} & \multicolumn{2}{|c|}{$\begin{array}{c}\text { Ameaça } \\
\text { generalizada à } \\
\text { propriedade } \\
\text { privada }\end{array}$} & \multicolumn{2}{|c|}{$\begin{array}{c}\text { Ameaça } \\
\text { generalizada aos } \\
\text { valores morais e } \\
\text { religiosos de } \\
\text { nossa sociedade }\end{array}$} & \multicolumn{2}{|c|}{$\begin{array}{l}\text { Descontrole da } \\
\text { corrupção }\end{array}$} & \multicolumn{2}{|c|}{$\begin{array}{l}\text { Ameaça ao } \\
\text { Estado pelo } \\
\text { crime } \\
\text { organizado }\end{array}$} & \multicolumn{2}{|c|}{$\begin{array}{l}\text { O fim do regime } \\
\text { democrático não } \\
\text { é aceitável em } \\
\text { hipótese alguma }\end{array}$} \\
\hline & Concordo & Discordo & Concordo & Discordo & Concordo & Discordo & Concordo & Discordo & Concordo & Discordo \\
\hline $\begin{array}{l}\text { Extrema- } \\
\text { direita }\end{array}$ & $\begin{array}{c}1 \\
100 \%\end{array}$ & 0 & $\begin{array}{c}1 \\
100 \%\end{array}$ & 0 & $\begin{array}{c}1 \\
100 \%\end{array}$ & 0 & $\begin{array}{c}1 \\
100 \%\end{array}$ & 0 & 0 & $\begin{array}{c}1 \\
100 \%\end{array}$ \\
\hline Centro-direita & $\begin{array}{c}3 \\
60 \%\end{array}$ & $\begin{array}{c}2 \\
40 \%\end{array}$ & $\begin{array}{c}3 \\
60 \%\end{array}$ & $\begin{array}{c}2 \\
40 \%\end{array}$ & $\begin{array}{c}3 \\
60 \%\end{array}$ & $\begin{array}{c}2 \\
40 \%\end{array}$ & $\begin{array}{c}2 \\
40 \%\end{array}$ & $\begin{array}{c}3 \\
60 \%\end{array}$ & $\begin{array}{c}2 \\
40 \%\end{array}$ & $\begin{array}{c}3 \\
60 \%\end{array}$ \\
\hline Centro & $\begin{array}{c}8 \\
80 \%\end{array}$ & $\begin{array}{c}2 \\
20 \%\end{array}$ & $\begin{array}{c}7 \\
70 \%\end{array}$ & $\begin{array}{c}3 \\
30 \%\end{array}$ & $\begin{array}{c}7 \\
70 \%\end{array}$ & $\begin{array}{c}3 \\
30 \%\end{array}$ & $\begin{array}{c}6 \\
60 \%\end{array}$ & $\begin{array}{c}4 \\
40 \%\end{array}$ & $\begin{array}{c}5 \\
50 \%\end{array}$ & $\begin{array}{c}5 \\
50 \%\end{array}$ \\
\hline $\begin{array}{l}\text { Centro- } \\
\text { esquerda }\end{array}$ & $\begin{array}{c}4 \\
25 \%\end{array}$ & $\begin{array}{c}12 \\
75 \%\end{array}$ & $\begin{array}{c}3 \\
18,8 \%\end{array}$ & $\begin{array}{c}13 \\
81,3 \%\end{array}$ & $\begin{array}{c}3 \\
18,8 \%\end{array}$ & $\begin{array}{c}13 \\
81,3 \%\end{array}$ & $\begin{array}{c}2 \\
12,5 \%\end{array}$ & $\begin{array}{c}14 \\
87,5 \%\end{array}$ & $\begin{array}{c}13 \\
81,3 \%\end{array}$ & $\begin{array}{c}3 \\
18,8 \%\end{array}$ \\
\hline Esquerda & 0 & $\begin{array}{c}6 \\
100 \%\end{array}$ & 0 & $\begin{array}{c}6 \\
100 \%\end{array}$ & $\begin{array}{c}1 \\
16,7 \%\end{array}$ & $\begin{array}{c}5 \\
83,3 \%\end{array}$ & $\begin{array}{c}1 \\
16,7 \%\end{array}$ & $\begin{array}{c}5 \\
83,3 \%\end{array}$ & $\begin{array}{c}5 \\
83,3 \%\end{array}$ & $\begin{array}{c}1 \\
16,7 \%\end{array}$ \\
\hline $\begin{array}{l}\text { Extrema- } \\
\text { esquerda }\end{array}$ & 0 & $\begin{array}{c}1 \\
100 \%\end{array}$ & 0 & $\begin{array}{c}1 \\
100 \%\end{array}$ & 0 & $\begin{array}{c}1 \\
100 \%\end{array}$ & 0 & $\begin{array}{c}1 \\
100 \%\end{array}$ & $\begin{array}{c}1 \\
100 \%\end{array}$ & 0 \\
\hline NR & $\begin{array}{c}1 \\
100 \%\end{array}$ & $\begin{array}{c}1 \\
50 \%\end{array}$ & $\begin{array}{c}2 \\
100 \%\end{array}$ & 0 & $\begin{array}{c}2 \\
100 \%\end{array}$ & 0 & $\begin{array}{c}2 \\
100 \%\end{array}$ & 0 & $\begin{array}{c}1 \\
50 \%\end{array}$ & $\begin{array}{c}1 \\
50 \%\end{array}$ \\
\hline Total & $\begin{array}{c}17 \\
41,5 \%\end{array}$ & $\begin{array}{c}24 \\
58,5 \%\end{array}$ & $\begin{array}{c}16 \\
39 \%\end{array}$ & $\begin{array}{c}25 \\
61 \%\end{array}$ & $\begin{array}{c}17 \\
41,5 \%\end{array}$ & $\begin{array}{c}24 \\
58.5 \%\end{array}$ & $\begin{array}{c}14 \\
34,1 \%\end{array}$ & $\begin{array}{c}27 \\
65,9 \%\end{array}$ & $\begin{array}{c}27 \\
65,9 \%\end{array}$ & $\begin{array}{c}14 \\
34,1 \%\end{array}$ \\
\hline
\end{tabular}

Fonte: Núcleo de Pesquisa em Sociologia Política Brasileira/UFPR. 


\section{Referências Bibliográficas}

ALMOND, G; VERBA, S. The civic culture: political attitudes and democracy in five nations. California: Sage Publications, 1989.

CONVERSE, P. E. The nature of belief systems in massa publics. In: APTER, D. E. (ed.). Ideology and discontent. New York: The Free Press, 1964, p. 206-261.

CARVALHO, J. M. A construção da ordem e teatro de sombras. $3^{\text {a }}$ ed. Rio de Janeiro: Civilização Brasileira, 2003.

DRUCKMAN, J. N.; NELSON, K. R. Framing and deliberation: how citizens' conversations limit elite influence. American Journal of Political Science, v. 47, n. 4, p. 729.745, 2003.

DAHL, R. A. Poliarquia. São Paulo: Edusp, 1997.

GERRING, J. What is a case study and what is it good for? American Political Science Review, v. 98, n. 2, p. 341-354, 2004.

INGLEHART, R. The renaissance of political culture. American Political Science Review, v. 82, n. 4 , p. 1203-1229, 1988.

LAMOUNIER, B. Do modelo institucional dos anos 30 ao fim da era Vargas. In: D'ARAUJO, M. C. (org.). As instituições brasileiras da era Vargas. Rio de Janeiro: EdUERJ/Editora da FGV, 1999, p. 35-53.

LANE, R. Political culture: residual category or general theory?. Comparative Political Studies, v. 25, n. 3, p. 362-387, 1992.

LATINOBARÓMETRO. Informe - Resumen Latinobarómetro 2004: uma década de mediciones. 2004, p. 4-5. Disponível em: <http://www.latinobarómetro.org>

LIJPHART, A. The structure of inference. In: ALMOND, G.; VERBA, S. (ed.). The civic culture revisited. Boston: Little, Brown and Company, 1980, p. 37-56.

LIMA, M. R. S.; CHEIBUB, Z. B. Elites estratégicas e dilemas do desenvolvimento. Rio de Janeiro: luperj, 1994. 
Instituições e valores: as dimensões da democracia na visão da elite brasileira, Revista Brasileira de Ciências Sociais, São Paulo, n. 31, p. 83-110, 1996.

LIMONGI, F. Debate institucional e democracia no Brasil: o problema do sistema partidário. In: PERISSINOTTO, R. M.; FUKS, M. (org.). Democracia: teoria e prática. Rio de Janeiro:

Relume Dumará, 2002, p. 55-72.

LOVE, J. A locomotiva: São Paulo na Federação Brasileira (1889-1937). Rio de Janeiro: Paz e Terra, 1982.

MCDONOUGH, P. Power and ideology in Brazil. New Jersey: Princeton University Press, 1981.

MOISÉS, J. A. Os brasileiros e a democracia: bases sócio-políticas da legitimidade democrática. São Paulo: Ática, 1995.

2005.

A desconfiança nas instituições democráticas. Opinião Pública, v. 11, n. 1, p. 33-63,

MUSZYNSKI, J.; MENDES, A. M. T. Democratização e opinião pública no Brasil. In:

LAMOUNIER, B. (org.). De Geisel a Collor: o balanço da transição. São Paulo: IDESP/Sumaré, 1990, p. $61 \cdot 80$.

PATEMAN, C. The civic culture: a philosophic critique. In: ALMOND, G.; VERBA, S. (ed.). The civic culture revisited. Boston: Little, Brown and Company, 1980, p. 57-102.

Participação e teoria democrática. Rio de Janeiro: Paz e Terra, 1992.

POWER, T.; JAMISON, G. D. Desconfiança política na América Latina. Opinião Pública, v. 11, n. 1, p. 64-93, 2005.

PRZEWORSKI, A.; CHEIBUB, J. A.; LIMONGI, F. Democracia e cultura: uma visão não culturalista. Lua Nova, São Paulo, n. 58, p. 9-35, 2003.

PUTNAM, R. D. Comunidade e democracia: a experiência da Itália moderna. $3^{\mathrm{a}}$ ed. Rio de Janeiro: FGV, 2002.

The comparative study of political elites. New Jersey: Printice-Hall, 1976. 
REIS, P. E.; CHEIBUB, B. Z. Valores políticos das elites e consolidação democrática. In: DADOS - Revista de Ciências Sociais, Rio de Janeiro, v. 38, n. 1, p. 31-56, 1995.

RODRIGUES, L. M. Partidos, ideologia e composição social: um estudo das bancadas partidárias na Câmara dos Deputados. São Paulo: Edusp, 2002.

SANTOS, F. (org.). O poder legislativo nos estados: diversidade e convergência. Rio de Janeiro: FGV, 2001.

SANTOS, A. M. Democracia e valores cívicos: uma relação necessária?. Novos Estudos Cebrap, São Paulo, v. 69, p. 145-160, 2004.

SEARING, D. Political involvement and socialization in Great Britain. In: CLARKE, H. D.; CZUDNOWSKI, M. M. (ed.). Political elites in anglo-american democracies: chances in stables regimes. Illinois: Northern Illinois University Press, 1987, p. 109-146.

VERBA, S. On revisiting the civic culture: a personal proscript. In: ALMOND, G.; VERBA, S. The civic culture revisited. Boston: Little, Brown and Company, 1980, p. 394-410.

WEDEEN, L. Conceptualizing culture: possibilities for political science. American Political Science Review, v. 96, n. 4, 2002. 